\title{
Major orthopaedic surgery on the leg and thromboembolism
}

\section{Prophylaxis now or negligence claims later}

The increased risk of thromboembolic complications in patients undergoing major surgery on the leg has been recognised for many years. About one in two patients will develop a deep vein thrombosis after total hip replacement. One in 20 will have a pulmonary embolus, nearly half of these being fatal. Deep vein thrombosis and pulmonary embolus are both more likely after surgery for a fractured hip, which has a $7 \cdot 5 \%$ mortality from pulmonary embolus. As might be expected, a pulmonary embolus is more likely after a proximal vein thrombosis. ${ }^{1}$

With more patients requiring hip and knee replacements as the population aged over 70 rises, more will be at risk of thromboembolism. As well as the mechanical trauma at the time of surgery, many of these aged, often frail, patients will have additional medical problems that will increase their risk of developing deep vein thromboses and fatal pulmonary emboli. They include obesity, cardiovascular disease, smoking, immobility, and possibly metabolic abnormalities such as diabetes mellitus.

Does prophylaxis reduce this high risk of venous thromboembolism, and, if so, why is it not employed more widely? How warranted are orthopaedic surgeons' fears of intraoperative and postoperative bleeding from the trauma to bone and muscle?

Prophylaxis has conclusively been shown to reduce the risk of thromboembolism, with an acceptably small risk of troublesome bleeding. Of the reluctance to give these patients anticoagulant drugs in the United Kingdom, however, there is no doubt. A survey of the use of thromboprophylaxis by British orthopaedic surgeons gives the reasons for their reluctance ( $p$ 549). ${ }^{2}$ The uncertainty lies not in the efficacy of prophylaxis (as an earlier study suggested ${ }^{3}$ ) but in which pharmacological agent is best. Many regimens have been evaluated over the past 20 years. Physical methods-for example, thigh length elastic stockings and external pneumatic compression-and drugs-for example, dextran; warfarin; fixed or titrated doses of heparin, either alone or in combination with dihydroergotamine; and antiplatelet drugs such as aspirin and dipyridamole - all have their advocates. ${ }^{+7}$ Early mobilisation is advocated to prevent deep vein thrombosis. ${ }^{68}$

The international multicentre trial showed that low dose subcutaneous heparin conferred a clear advantage in reducing the frequency of fatal pulmonary embolus in patients aged over 40 having elective major general surgery. ${ }^{9}$ Wound haematomas occurred in a small but appreciable number, but clinically important bleeding was not increased. Almost 20 years have elapsed since orthopaedic surgeons first assessed the value of low dose subcutaneous (unfractionated) heparin in hip surgery, and, despite what seems to be strong evidence of its efficacy in reducing deep vein thromboses and pulmonary emboli, many surgeons remain reluctant to give anticoagulants to these patients.

With the introduction of low molecular weight heparin the time has come to restate the case for prophylaxis against thromboembolism. Low molecular weight heparin is a fractionated compound with higher bioavailability than unfractionated heparin which enhances the inhibition of factor Xa with only minimal inhibition of thrombin, needed for local haemostasis at the site of the operation. ${ }^{111}$ It has less effect on platelet aggregation and is less likely to cause thrombocytopenia. Its longer biological half life allows for once daily injection, and it seems safer and more effective than standard low dose unfractionated heparin. ${ }^{12-15}$ The paper by Leyvraz and colleagues in this issue reports the results of a large European trial which comes down strongly in favour of low molecular weight heparin over unfractionated heparin. It found a $78 \%$ reduction in the risk of proximal vein thrombosis, with no increase in bleeding complications ( $p$ 543). ${ }^{16}$

Several studies have established that empirical dose regimens do not result in effective anticoagulation. Laboratory control may be required, and now that many laboratories can measure the antifactor Xa activity, treatment can be more finely tuned. The dose should be adjusted for weight ${ }^{17}$ and possibly for other factors, such as skinfold thickness, which may affect absorption. ${ }^{18}$ Treatment should be started 12 hours before surgery and continued for seven to 10 days postoperatively or until the patient is mobile.

Does oral anticoagulant treatment have a role? Warfarin has its supporters as it substantially reduces the incidence of venous thrombosis without causing excessive loss of blood. It should be started 10-14 days before surgery, and the international normalised ratio should be maintained around $1 \cdot 3$, which will not compromise haemostasis. (This probably restricts its use to elective surgery.) After surgery the dose of warfarin. should be increased to achieve an international normalised ratio of 2-3. The two step method of Francis et al effectively achieves this objective. ${ }^{19}$ Two recent studies were unable to show any benefit from fixed minidose warfarin in total hip replacement. ${ }^{2021}$

Which prophylactic regimen is best? For a fractured hip little choice exists; for elective total hip replacement the choice is between subcutaneous heparin and warfarin. Low molecular weight heparin once daily seems as effective as 
conventional unfractionated heparin given twice or three times a day. These three agents have not yet been compared directly in a single study.

What is needed is the most effective drug with the simplest method of administration and control and the smallest risk of adverse effects. In these days of cost effectiveness the modest cost of prophylactic treatment must be measured against the considerable risk of thromboembolic complications of hip surgery if no prophylaxis is given, with the cost of the increased length of stay in hospital, morbidity, and mortality. How long anticoagulants should be continued postoperatively has not been determined; most series have recorded late presentations of thromboembolic complications after discharge from hospital. What is inescapable is the need for prophylaxis.

Consultant Haematologist

J PARKER-WILLIAMS

Consultant Orthopaedic Surgeon

ROGER VICKERS

St George's Hospital,

London SW 17 0QT

1 Haake DA, Berkman SA. Venous thromboembolic disease after hip surgery. Risk factors, prophylaxis and diagnosis. Clin Orthop 1989;242:212-31.

2 Laverick MD, Croal SA, Mollan RAB. Orthopaedic surgeons and thromboprophylaxis. BMF 1991;303:549-50.

3 Brenkel IJ, Clancy MJ. Total hip replacement and antithrombotic prophylaxis. $\mathrm{Br} f \mathrm{Hosp}$ Med 1989;42:282-4.

4 Harris WH, Salzman EW, Athanasoulis C, Waltman AC, Baum S, DeSanctis RW, et al. Comparison of warfarin, low-molecular-weight dextran, aspirin, and subcutaneous heparin in 1974;56:1552-62.

5 Moskovitz PA, Ellenberg SS, Feffer HL, Kenmore PI, Neviaser RJ, Rubin BE, et al. Low-dose heparin for prevention of venous thromboembolism in total hip arthroplasty and surgical repair of hip fractures. F Bone foint Surg [Am] 1978;60:1065-70.

6 Consensus Conference. Prevention of venous thrombosis and pulmonary embolism. FAMA 1986;256:744-9.

7 Leyvraz PF, Richard J, Bachmann F, Van Melle G, Treyvaud J-M, Livio J-J, et al. Adjusted versu fixed-dose subcutaneous heparin in the prevention of deep-vein thrombosis after total hip red

8 Lassen MR, Borris LC. Mobilisation after hip surgery, and efficacy of thromboprophylaxis. Lance 1991;337:618.

9 International Multicentre Trial. Prevention of fatal postoperative pulmonary embolism by low doses of heparin. Lancet 1975; ii:45-51.

10 Thomas DP. Current status of low molecular weight heparin. Thromb Haemost 1986;56:241-2.

11 Salzman EW. Low-molecular-weight heparin. Is small beautiful? N Engl f Med 1986;315:957-9.

12 Planes A, Vochelle N, Mazas F, Mansat C, Zucman J, Landais A, et al. Prevention of postoperative venous thrombosis: a randomized trial comparing unfractionated heparin with low molecular weight heparin in patients undergoing total hip replacement. Thromb Haemost 1988;60:407-10

13 Matzsch T, Bergqvist D, Fredin H, Hedner U. Low molecular weight heparin compared with dextran as prophylaxis against thrombosis after total hip replacement. Acta Chir Scand 1990;156:445-50

14 Lassen MR, Borris LC, Christiansen HM, Boll KL, Eiskjaer SP, Nielsen BW, et al. Prevention of thromboembolism in 190 hip arthroplasties. Comparison of low molecular weight heparin and placebo. Acta Orthop Scand 1991;62:33-8.

15 Turpie AGG, Levine MN, Hirsh J, Carter CJ, Jay RM, Powers PJ, et al. A randomized controlled trial of low-molecular weight heparin (Enoxaprin) to prevent deep-vein thrombosis in patients undergoing elective hip surgery. $N$ Engl f Med 1986;315:925-9.

16 Leyvraz PF, Bachmann F, Hoek J, Buller MH, Postel M, Samama M, et al. Prevention of deep vein thrombosis after hip replacement. Randomised comparison between unfractionated heparin and low molecular weight heparin. BMF 1991;303:543-8.

17 Vitoux JF, Aiach M, Roncato M. Fiessinger JN Should thromboprophylactic dosage of low molecular weight heparin be adapted to patient's weight? Thromb Haemost 1988;59:120.

18 Kroon C, de Boer A, Kroon JM, Schoenmaker HC, vd Meer FJM, Cohen AF, et al. Influence of skinfold thickness on heparin absorption. Lancet 1991;337:945-6.

19 Francis CW, Marder VJ, Evarts CMcC, Yaukoolbodi S. Two-step warfarin therapy Prevention of postoperative venous thrombosis without excessive bleeding. FAMA 1983;249:374-8.

20 Fordyce MJF, Baker AS, Staddon GE. Efficacy of fixed minidose warfarin prophylaxis in total hip replacement. BMF 1991;303:219-20.

21 Dale C, Gallus A, Wycherley A, Langlois S, Howie D. Prevention of venous thrombosis with minidose warfarin after joint replacement. BMF 1991;303:224.

\section{Advances in cell kinetics}

Abnormal proliferation of cells is an important feature of many diseases, particularly malignancy. Knowledge of the proliferative characteristics, or cell kinetics, of tumours may help to unravel the disease process and to optimise the timing of treatment.

Proliferating cells pass through a series of discrete phases in their life cycle. Howard and Pelc, responsible for the modern concept of the cell cycle, described five phases. ${ }^{1}$ From the G1 (gap 1) phase cells enter either the G0 (resting) or S (DNA synthesis) phase. From the S phase they enter the G2 (gap 2) phase, from which they pass into the $M$ (mitosis) phase and then back into G1. Chromosomes are duplicated during the $S$ phase. The timing of the $S, G 2$, and $M$ phases is relatively constant for any one cell type, maximum variation being found in the Gl phase. The importance of this model of the cell cycle is that complex populations of cells become amenable to experimental and mathematical analysis.

The dissection of the cell cycle requires the labelling of newly synthesised DNA with a detectable precursor molecule. Until recently, tritiated thymidine was the mainstay of research into cell kinetics. ${ }^{2}$ This restricted the study of the proliferation of human tumours to in vitro incubation of freshly excised tumour biopsy specimens with ${ }^{3} \mathrm{H}$ thymidine. Autoradiography allowed the estimation of the labelling index, but time dependent measurements - such as the cell cycle time-could be estimated only if multiple, serial biopsy specimens were taken. This was rarely feasible in clinical practice.

Bromodeoxyuridine (BrdUrd) and iododeoxyuridine (IdUrd) are halogenated analogues of thymidine which have long been in clinical use as radiosensitisers. They are reliably incorporated into the DNA of proliferating cells. In 1982 Gratzner $^{3}$ and colleagues ${ }^{4}$ in the United States developed a family of monoclonal antibodies that detected these analogues bound within DNA. Proliferating cells could therefore be identified by immunohistochemical examination.

Developments in flow cytometry have greatly enhanced the use of this technique. ${ }^{5}$ In a flow cytometer laser light illuminates a stream of suspended cells or nuclei. If these are labelled with monoclonal antibodies and fluorescent dyes, then simultaneous quantitative measurement of multiple factors - for example, the DNA content and the content of bromodeoxyuridine - is possible in each of thousands of cells.

In 1985 Begg and colleagues described a flow cytometric technique by which a cohort of tumour cells labelled with bromodeoxyuridine could be followed through their cell cycle. ${ }^{67}$ From this the tumour labelling index, the duration of the $S$ phase, and the potential doubling time of the tumour could be estimated. The method has been shown to be applicable to human tumours in vivo. ${ }^{89}$ The derivation of time dependent measures of proliferation from a single biopsy specimen of a tumour or tissue pulse labelled in vivo is now possible. Bromodeoxyuridine can be given as a $250 \mathrm{mg}$ intravenous bolus before surgery or biopsy for cancer. Bromodeoxyuridine shares a small risk of mutagenicity with all cytotoxic agents and ionising radiations, and prudence suggests that currently its use should be confined to adults above reproductive age with proved malignancy.

Considerable work is still needed to standardise analytical protocols and to assess the effect of tumour heterogeneity on the interpretation of results. Nevertheless, the technique marks a noteworthy advance in oncological research. ${ }^{111}$ Proliferation indices are currently being assessed both as predictors of clinical outcome $\mathrm{e}^{1213}$ and as guides to the fractionation of adjuvant treatment for cancer. For example, rapid proliferation of cells and tumour repopulation could 